\title{
Relationship between clinical severity of respiratory syncytial virus infection and subtype
} M C J Kneyber, A H Brandenburg, Ph H Rothbarth, R de Groot, A Ott,
H A van Steensel-Moll

Abstract

The relationship between clinical severity of respiratory syncytial virus (RSV) infection and distribution of subtype $A$ or $B$ was investigated. The data of 232 children, who were admitted with RSV infection or diagnosed in the outpatient department of the Sophia Children's Hospital, Rotterdam between 1992 and 1995, were studied. The diagnosis of RSV was confirmed by a direct immunofluorescence assay. Subtyping was performed by an indirect immunofluorescence assay using specific monoclonal antibodies. Gender, age at diagnosis, gestational age and birth weight, the presence of underlying diseases, feeding difficulties, the presence of wheezing and retractions, respiratory rate, temperature, clinical diagnosis at presentation, oxygen saturation $\left(\mathrm{SaO}_{2}\right)$, carbon dioxide tension $\left(\mathrm{PCO}_{2}\right)$, and $\mathbf{p H}$, characteristics of hospitalisation, and the need for mechanical ventilation were observed. Analysis was performed on data from all patients diagnosed with RSV infection in the period between 1992 and 1995 spanning three RSV seasons, and separately on the RSV season 1993-4. The outcome of the three year analysis (150 (64.7\%) subtype A $v 82$ (35.3\%) subtype B) was compared with the outcome of the season 1993-4, a mixed epidemic with 37 (60.7\%) subtype $A$ and 24 (39.3\%) subtype $B$ isolates. None of the variables observed in the season 1993-4 differed significantly between RSV subtype $A$ and $B$. Similar results were obtained from the analysis in the period 1992 until 1995, with the exception of $\mathrm{PCO}_{2}$ (a higher $\mathrm{PCO}_{2}$ was found in subtype $A, p<0.001)$ and retractions (more retractions were noted in patients with subtype $A, p=0.03$ ). After correcting for possible confounders using regression analysis, these differences were not significant anymore. The data indicate that there is no relationship between clinical severity of RSV infection and subtype. (Arch Dis Child 1996;75:137-140)

Keywords: respiratory syncytial virus, clinical severity of infection, subtype $A$ and $B$.

The Netherlands

A Ott

Correspondence to: Dr H A van Steensel-Moll, Sophia Children's Hospital, Dr Molewaterplein 60,3015 Gr Rolewaterplein Netherlands.

Accepted 24 April 1996
Respiratory syncytial virus (RSV) is the most common cause of respiratory tract infections in infants and young children. The clinical presentation can vary from a mild upper respiratory tract infection to severe bronchiolitis.
The incidence of RSV bronchiolitis reaches a maximum at the age of 2 months and declines within the first year of life. ${ }^{1}$ The majority of infections have a mild clinical course. A minority of infants, 0.5 to $2 \%$, has to be admitted to the hospital. Between $7 \%$ and $21 \%$ of these patients will need mechanical ventilation. ${ }^{23}$

Severe infections may occur in premature infants or patients suffering from an underlying disease, such as congenital heart disease, bronchopulmonary dysplasia, or $\mathrm{T}$ cell immunodeficiency. ${ }^{4}$ The mortality of infants hospitalised with $\mathrm{RSV}$ is approximately $0.5 \%$ to $1.5 \%$. In infants with an underlying disease higher mortality rates are found. ${ }^{56}$

Two major antigenic groups of RSV, subtype $A$ and subtype $B$, can be identified by specific monoclonal antibodies. ${ }^{7}$ The antigenic diversity between these two subtypes is determined mainly by $G$ proteins, which are responsible for attachment of the virus and to a lesser extent by the fusion proteins, the $\mathrm{F}$ proteins. The two subtypes can circulate independently from each other, but they may also cocirculate during one epidemic. ${ }^{8}$ The identification of the two subtypes has led to the speculation that there might be a relationship between clinical severity of infection and RSV subtype. A limited number of studies were carried out to establish such a relationship. ${ }^{9-12}$ These studies provided conflicting results.

The objective of our study was to investigate whether a relationship could be demonstrated between clinical severity of RSV infection and subtype in children younger than 12 months.

\section{Patients and methods}

Patients younger than 12 months who either were admitted to the Sophia Children's Hospital or visited the outpatient department due to RSV infection in the period between 1992 and 1995, were included in this study. The Sophia Children's Hospital is a combined secondarytertiary care university hospital. RSV infection was confirmed by a positive direct immunofluorescence assay using fluorescein isothiocyanate (FITC) labelled monoclonal antibodies against RSV (Dako) performed on cells of nasopharyngeal washing and/or a positive viral culture on Hep 2 cells. ${ }^{13}$ In $97.4 \%(n=226)$ both the immunofluorescence assay and viral culture were positive, in $1.3 \%(n=3)$ only the immunofluorescence assay was positive, and in $1.3 \%(n=3)$ only the viral culture was positive. RSV subtyping was performed using RSV subtype specific antifusion protein monoclonal antibodies in an immunofluorescence assay on 
cells of nasopharyngeal washings as described by Taylor et al. ${ }^{14}$ Monoclonal antibodies used were $92-11 \mathrm{C}$ for subtype $A$ and $102-10 B$ for subtype $\mathrm{B}$ (Chemicon). ${ }^{7}$ Briefly, cells of nasopharyngeal washings were fixed on glass slides in acetone. RSV subtype specific monoclonal antibodies were incubated for 30 minutes at $37^{\circ} \mathrm{C}$. After washing three times in phosphate buffered saline the slides were incubated with the conjugate antimouse FITC (Dako) for 30 minutes at $37^{\circ} \mathrm{C}$ and washed again. When the immunofluorescence assay was negative and viral culture was positive, subtype specific immunofluorescence was performed on RSV infected Hep 2 cells.

Epidemiological and clinical data were retrospectively obtained from the medical charts. Demographic parameters included gender, age at diagnosis, birth weight, gestational age, and the presence of underlying disease (congenital heart disease with haemodynamic consequences, that is a left/right shunt, bronchopulmonary disease, and $\mathrm{T}$ cell immunodeficiency). Clinical observations at presentation included feeding difficulties (defined as normal feeding, slow feeding with normal volume, decreased volume, and no oral feeding), the presence of wheezing and retractions, and temperature. The use of mechanical ventilation was registered during admission. The decision for admission to the intensive care unit and mechanical ventilation was made before subtype was known. Other clinical parameters included characteristics of hospitalisation: number of admissions and length of stay in hospital and number of intensive care unit admissions and length of stay in intensive care.

Laboratory parameters measured at presentation included measurement of oxygen saturation $\left(\mathrm{SaO}_{2}\right)$, carbon dioxide tension $\left(\mathrm{PCO}_{2}\right)$, and $\mathrm{pH} . \mathrm{SaO}_{2}$ was measured transcutaneously with the use of a pulse oximeter and $\mathrm{PCO}_{2}$ on capillary blood samples. All parameters were measured irrespective of severity of disease. Three diagnostic categories were defined: bronchiolitis/pneumonia (lower respiratory tract infection), upper respiratory tract infection, and apnoea. The diagnosis of bronchiolitis was based on clinical features and hypertranslucency, atelectasis, or bronchial thickening on chest radiography. Upper respiratory tract infection was defined as coughing

Table 1 Patient characteristics

\begin{tabular}{|c|c|c|}
\hline & Subtype $A(n=150)$ & Subtype $B(n=82)$ \\
\hline Boys/girls (\%) & $63.3 / 36.7$ & $67.1 / 32.9$ \\
\hline \multicolumn{3}{|l|}{ Age (months) } \\
\hline Mean (SD) & $3.5(3.0)$ & $3.6(2.9)$ \\
\hline$<3$ months (\%) & 48.0 & 47.6 \\
\hline 3- 6 months (\%) & 26.7 & 26.8 \\
\hline$>6$ months $(\%)$ & 25.3 & 25.6 \\
\hline \multicolumn{3}{|l|}{ Gestational age (weeks) } \\
\hline Mean (SD) & $37.3(3.8)$ & $37.8(3.3)$ \\
\hline$\leqslant 34$ weeks $(\%)$ & 18.4 & 12.7 \\
\hline $35-37$ weeks $(\%)$ & 10.3 & 12.7 \\
\hline$\geqslant 37$ weeks $(\%)$ & 71.3 & 74.6 \\
\hline Mean (SD) birth weight (g) & $2936.0(875)$ & $3023.0(804)$ \\
\hline Underlying disease state $(\%)$ & 16.3 & 11.0 \\
\hline Prematurity and BPD (n) & 10 & 4 \\
\hline CHD (n) & 14 & 3 \\
\hline$B P D(n)$ & 0 & 2 \\
\hline
\end{tabular}

No significant differences between RSV subtype $A$ and B were found. and/or rhinitis, with no abnormalities on chest radiography. Apnoea at presentation was defined as a cessation of respiration for a period over 15 seconds and/or bradycardia with accompanying cyanosis. The diagnosis pneumonia was based on clinical features and the presence of an infiltrate on chest radiography.

Statistical analysis was performed using the $\chi^{2}$ test and Student's $t$ test; a p value $\leqslant 0.05$ was considered significant. In order to examine the independent effect of virus subtype on the severity of disease we adjusted for gender, age in months, prematurity (gestational age $\leqslant 37$ weeks), the presence of underlying disease, and year of diagnosis with logistic and linear regression analysis. Linear regression was used to investigate if there were differences between the two virus subtypes in $\mathrm{SaO}_{2}$ or $\mathrm{PCO}_{2}$. Logistic regression was performed with dichotomous outcome variables such as feeding difficulties, the presence of retractions and wheezing, the diagnosis of bronchiolitis or pneumonia compared with upper respiratory tract infection, need of mechanical ventilation and intensive care unit admission.

\section{Results}

In the period between 1992 and 1995 covering three RSV seasons, 232 children with RSV infection visited our hospital. In 1992-3 a predominance of subtype $B$ was found. Ten out of 68 children were infected with subtype A (14.7 \%) compared with 58 children with subtype B (85.3\%). The season 1993-4 showed a mixed epidemic: 37 children were infected with subtype A $(60.7 \%)$ and 24 with subtype B (39.3\%). The season 1994-5 showed a epidemic in which all 103 children were infected with subtype A. Based upon the subtype distribution, two analysis were performed: one on the entire period from 1992 until 1995, covering three RSV seasons and one on the mixed A/B season 1993-4. The results of the outcome of the analysis of the period 1992-5 were compared with the outcome of the analysis of the season 1993-4.

ANALYSIS OF THE DATA FROM 1992-5

This period included 232 children: 150 $(64.7 \%)$ were infected with subtype $A$ and 82 (35.3\%) with subtype B. The male/female ratio was $1.8(150 / 82)$. Table 1 summarises the population characteristics.

Clinical parameters are shown in table 2. No significant differences were found for feeding difficulties, the presence of wheezing, respiratory rate, temperature, $\mathrm{SaO}_{2}$, and $\mathrm{pH}$. Significant differences were found for $\mathrm{PCO}_{2}$ and the presence of retractions. The average $\mathrm{PCO}_{2}$ for subtype $A$ is $6.8 \mathrm{kPa}$ compared with $5.8 \mathrm{kPa}$ for subtype $B(p<0.001)$. Retractions were noted in 84 children infected with subtype $A$ and in 28 children infected with subtype $B$ $(p=0.03)$. No significant differences were found regarding underlying disease.

Table 3 shows the clinical diagnosis at presentation and table 4 the characteristics of hospitalisation. 
Table 2 Clinical parameters at presentation

\begin{tabular}{lll}
\hline & Subtype $A(n=150)$ & Subtype $B(n=82)$ \\
\hline Feeding difficulties (\%) & 71.6 & 64.6 \\
Wheezing (\%) & 36.0 & 34.1 \\
Retractions (\%) & 58.0 & 41.8 \\
Mean (SD) respiratory rate (per min) & $52(18)$ & $51(13)$ \\
Mean (SD) temperature ( $\left.{ }^{\circ} \mathrm{C}\right)$ & $37.8(1.0)$ & $38.0(0.8)$ \\
Mean (SD) $\mathrm{SaO}_{2}$ (\%) & $90.3(11.3)$ & $90.4(9.2)$ \\
Mean (SD) $\mathrm{PcO}_{2}(\mathrm{kPa})$ & $6.8(2.2)$ & $5.8(1.0)$ \\
Mean (SD) $\mathrm{pH}$ & $7.35(0.1)$ & $7.37(0.1)$ \\
\hline
\end{tabular}

No significant differences between RSV subtype A and B were found, except for the presence of retractions $(p=0.03)$ and $\mathrm{PCO}_{2}(p<0.001)$.

Table 3 Clinical diagnosis at presentation (\%)

\begin{tabular}{lcc}
\hline & Subtype $A(n=150)$ & Subtype B $(n=82)$ \\
\hline Apnoea I URTI & 5.3 & 3.7 \\
URTI & 24.7 & 28.0 \\
Bronchiolitis/pneumonia & 3.3 & 2.4 \\
With URTI & 52.0 & 56.1 \\
With apnoea and URTI & 14.7 & 9.8
\end{tabular}

No significant differences between subtype $A$ and $B$ were found.

URTI: upper respiratory tract infection.

Table 4 Characteristics of hospitalisation

\begin{tabular}{llc}
\hline & Subtype A $(n=150)$ & Subtype B (n=82) \\
\hline Admissions (\%) & 76.7 & 85.4 \\
Mean (SD) length of stay (days) & $10.4(6.2)$ & $9.3(4.8)$ \\
ICU admissions (\%) & 34.0 & 23.2 \\
Mean (SD) length of stay in ICU (days) & $6.2(8.3)$ & $5.9(5.0)$ \\
Mechanical ventilation (\%) & 14.0 & 8.5 \\
\hline
\end{tabular}

No significant differences between RSV subtype A and B were found.

ICU: intensive care unit.

The $\mathrm{PCO}_{2}$ was measured in 213 children: $136(90.1 \%)$ samples were collected in patients with subtype A and 77 (94.0\%) for subtype B. We noted in the season $1994-5$ that there were more children with a high $\mathrm{PCO}_{2}$ (above 10.0 $\mathrm{kPa}$ ) than in the other two seasons. We also found in the season 1994-5 a significant difference in the number of children $<2$ months of age (in the first two seasons $19.4 \%$ against $34.0 \%$ of the children in the season 1994-5, $\mathrm{p}=0.01$ ). Furthermore we found a significantly higher $\mathrm{PCO}_{2}$ in children $<2$ months of age $(7.5 \mathrm{kPa} v 6.0 \mathrm{kPa}$ for children $\geqslant 2$ months of age, $p<0.001$ ). This also applies to all three seasons separately.

Twenty eight $(12.1 \%)$ children required mechanical ventilation. Twenty one of these were infected with subtype $A$ and seven with subtype $B(p=0.22)$. Two children died; one of them was infected with subtype $A$ and the other with subtype $B$.

Adjustment for confounders with regression analysis did not reveal a significant difference between subtype $A$ and $B$ for any of the disease outcome parameters such as presence of retractions, presence of wheezing, feeding difficulties, $\mathrm{SaO}_{2}$ and $\mathrm{PCO}_{2}$, lower respiratory tract infection, admission to intensive care, and mechanical ventilation.

ANALYSIS OF THE 1993-4 SEASON AND

COMPARISON OF BOTH ANALYSIS

This period included 61 patients. The male/ female ratio was $1.3(35 / 26)$. We did not find a significant difference in the studied population characteristics between subtype $A$ and subtype $B$.
Significant differences were not found between subtype A and subtype B for all the observed variables. The outcome of the analysis of the data from the season 1993-4 was equal to the outcome of the analysis of the data from the period 1992-5, covering three separate $\mathrm{RSV}$ seasons, except for $\mathrm{PCO}_{2}$ and the presence of retractions.

\section{Discussion}

We investigated whether a relationship between clinical severity of RSV infection and subtype A or B could be demonstrated. The results of our study indicate that such a relationship does not exist.

Two analysis were performed: one on data from the whole period of 1992-5, covering three RSV seasons, and one on data of the season 1993-4. By comparing the outcome of one season with the outcome of three seasons, the possible effect of confounding variables from a particular season was ruled out.

$\mathrm{SaO}_{2}, \mathrm{PCO}_{2}$, clinical diagnosis (upper respiratory tract infection $v$ lower respiratory tract infection), admission to intensive care, and the need for mechanical ventilation were the parameters used to indicate the severity of infection. These indicators are strongly related to pulmonary dysfunction. ${ }^{10}$

None of the variables observed in the season 1993-4 were significantly different between patients infected with subtype $A$ and subtype B. This was also found in the analysis of the period 1992-5, except for the presence of retractions and $\mathrm{PCO}_{2}$. More retractions were noted in patients with subtype $A$ than in patients with subtype B. However, the association did not hold after correcting for confounders using logistic regression analysis.

The other variable that showed a significant difference in $\mathrm{PCO}_{2}$. Although it is a rather powerful indicator of severity, based on the outcome alone one cannot conclude that subtype $A$ is related to a more severe disease because of several reasons. First, other indicators of severity that precede a high $\mathrm{PCO}_{2}$ in RSV infection, such as hypoxaemia and respiratory rate, did not differ significantly between subtype A and subtype B. Second, $\mathrm{PCO}_{2}$ was measured in capillary blood samples, which is less reliable than measurements from arterial blood. We therefore developed the hypothesis that the difference in $\mathrm{PCO}_{2}$ between subtype $A$ and $B$ found in our study, is due to a relationship between age at diagnosis and $\mathrm{PCO}_{2}$. Mulholland et al demonstrated in their study that a significant relationship between young age and $\mathrm{PCO}_{2}$ exists. ${ }^{15}$ When examining the age distribution carefully, we find particularly in the season 1994-5, in which all children were infected with subtype A, significantly more children $<2$ months of age were admitted with RSV than in the two preceding epidemics. The mean $\mathrm{PCO}_{2}$ of these children is higher than the mean of children $\geqslant 2$ months. This influences the mean $\mathrm{PCO}_{2}$ for subtype $\mathrm{A}$ in the whole period covering the three separate RSV seasons. The hypothesis was tested using linear regression analysis. The analysis showed a significant relationship between young age 
and $\mathrm{PCO}_{2}$ and showed that the association between high $\mathrm{PCO}_{2}$ and subtype $\mathrm{A}$ did not hold after correcting for age, thus supporting our hypothesis.

Several studies investigated the possible relationship between clinical severity of RSV infection and subtype. McConnochie et al concluded that subtype $A$ is related to a more severe disease. ${ }^{9}$ They analysed data from 157 patients with known subtype, using arbitrary cut off values at which a variable was to be considered severe. Significant differences were observed in $\mathrm{PCO}_{2}>45 \mathrm{~mm} \mathrm{Hg}(6.00 \mathrm{kPa})$, $\mathrm{SaO}_{2}<87 \%$, and respiratory rate $>72 / \mathrm{min}$. A significant difference was also observed between subtype $A$ and subtype $B$ regarding mechanical ventilation. Straliotto et al concluded that subtype B is related to a more severe disease, but their population was rather small: 29 patients. ${ }^{11}$ The results of both these studies are conflicting with those from our study. McIntosh et al conclude that there is no difference in severity between subtype $A$ and subtype B. They analysed their data using a severity index consisting of three groups: severe, moderate, and mild. ${ }^{12}$

In conclusion, the outcome of the analysis of the data obtained in our study indicate that there is no relationship between clinical severity of RSV infection and subtype. Hence it is not necessary to determine subtype at presentation, because there are no consequences for clinical management. The outcome of our study also implies that the development of a vaccine has to aimed in the direction of a vaccine which protects for subtype $A$ as well as subtype $B$.
1 Parrot RH, Kim HW, Arrobio JO, et al. Epidemiology of respiratory syncytial virus infection in Washington, DC: infection and disease with respect to age, immunologic status, race and sex. Am $\mathcal{F}$ Epidemiol 1973; 98: 289-300.

2 Everard $\mathrm{ML}$, Milner $\mathrm{AD}$. The respiratory syncitial virus and its role in acute bronchiolitis. Eur $\mathcal{F}$ Pediatr 1992; 151: 63851

3 Frankel LR, Lewiston NJ, Smith DW, Stevenson DK. Clinical observations on mechanical ventilation for respiratory failure in bronchiolitis. Pediatr Pulmonol 1986; 79: 475-8.

4 Brunell PA, Daum RS, Hall CB, Lepow ML, McCracken GH Jr (Committee on Infectious Diseases 1986-1987). Ribavirin therapy of respiratory syncitial virus. Pediatrics 1987; 79: 475-6.

5 La Via WV, Grant SW, Stutman HR, Marks MI. Clinical profile of pediatric patients hospitalized with respiratory syncitial virus infection. Clin Pediatr (Phila) 1993; 32: 450-4.

6 La Via WV, Marks MI, Stutman HR. Respiratory syncitial virus puzzle: clinical features, pathophysiology, treatment and prevention. $\mathcal{F}$ Pediatr 1992; 121: 503-9.

7 Anderson LJ, Hierholzer JC, Tsou C, et al. Antigenic characterization of respiratory syncitial virus strains with mon.

8 Belshe RB, Mufson MA. Respiratory syncitial virus. In: Belshe RB, ed. Textbook of human virology. 2nd Ed. St Louis: Mosby Year Book, 1991: 388-402.

9 McConnochie KM, Hall CB, Walsh EE, Roghman KJ. Variation in severity of respiratory syncytial virus infections with subtype. F Pediatr 1990; 117: 52-62.

10 Hall CB, Walsh EE, Schnabel KC, et al. Occurrence of groups $A$ and $B$ of respiratory syncytial virus over 15 years: associated epidemiologic and clinical characteristics in hospitalized and ambulatory children. F Infect Dis 1990, 162: $1283-90$

11 Straliotto SM, Roitman B, Lima JB, Fischer GB, Siqueira MM. Respiratory syncytial virus bronchiolitis: competitive study of RSV groups A and B infected children. Rev Soc Bras Med Trop 1994; 27 : 1-4.

12 McIntosh DG, De Silva LM, Oates RK. Clinical severity of respiratory syncytial virus group $A$ and $B$ infection in Syd-

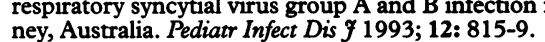

13 Minich LL, Ray CG. Comparison of direct and indirect immunofluorescence staining of clinical specimens for detection of respiratory syncytial virus antigen. $f$ Clin Microbiol 1982; 15: 969-70.

14 Taylor CE, Morrow S, Scott M, Young B, Toms GL. Comparative virulence of respiratory syncytial virus subgroups $A$ and B. Lancet 1989; i:777-8.

15 Mulholland EK, Olinsky A, Shann FA. Clinical findings and severity of acute bronchiolitis. Lancet 1990; 335: 1259-61. 